\title{
DETERMINING THE POTENTIAL BENEFITS FOR THE FREIGHT CARRIAGE BY ROAD IN SPAIN FACING AN INCREASE IN VEHICLES GVM 40 TO 44 TONS
}

\author{
José Magín Campos Cacheda
}

Associate Professor. Universidad Politécnica de Cataluña $\cdot$ BarcelonaTech

Adriana Haydee Martínez Reguero

Associate Professor. Universidad Politécnica de Cataluña · BarcelonaTech

\begin{abstract}
A very significant percentage of the products shipped by road in Spain using heavy goods vehicles (HGV) make 40 tons GVM (gross vehicle mass).

Any changes aimed at increasing productivity in that vehicles category would result in a very positive way in the road freight transport market, by lowering transport costs, decreasing environmental costs, rationalizing the sector and improving logistics market.

Therefore it is discussed here the improvement derived from the transfer of HGV that currently have a limitation of 40 tons GVM to a new limit of 44 tons GVM, establishing the potential benefits that would be set after the change.
\end{abstract}




\section{INTRODUCTION AND OBJECTIVES}

The load capacity of HGV is an essential factor of transport costs. The legislation has been accommodating the needs of transport companies so that the maximum authorized dimensions and weights have been increasing steadily over the years.

European Directive 96/53/EC establishes the maximum weight and dimensions of freight vehicles in international traffic. However, it states that Member States may authorize the movement within their territory of vehicles for national transport of goods which do not conform to the dimensions and weights indicated therein. Several European countries have made use of this power and have introduced regulations for the use of new transport capabilities.

Transportation with HGV of 44 tons GVM or above is generally allowed in many EU countries using five axle vehicles (T2S3: 2 axle tractor and 3 axle semi-trailer). In other countries, the use of HGV with 42 tons GVM is generally allowed. In Spain the use of HGV with 44 tons GVM are only allowed with 3 axle tractor (T3S2, T3S3) for combined transport, with ISO 40-foot container, and the limitation of $150 \mathrm{~km}$.

This study aims to analyze the impact of increased 44 tons GVM in Spain for T2S3 vehicles, commonly used in transportation. Knowledge of these data is intended to enable an objective analysis of the benefits and impacts that the introduction of this measure in Spain would involve.

\section{ANALYSIS OF FACTORS IMPACT}

\subsection{Scenarios considered}

In attracting goods to be transported from HGV of 40 tons GVM that are circulating at full capacity we have to keep in mind that there are a number of restrictions that prevent the complete transfer of the entire move merchandise by such vehicles. For this reason, we have identified two deployment scenarios: Scenario A, in which the collection of goods on HGV of 40 tons GVM that are circulating at full capacity is $80 \%$, and stage B, in which said uptake reaches $100 \%$.

Moreover, it has also taken into account the possibility of transfer goods from vehicles that currently circulate not fully loaded, but having a high value of use of their load capacity. Establish a transfer value for the goods transported by these categories of vehicles is complicated, but in response to similar studies we can accept as plausible uptake of goods transported by $15 \%$ in scenario A and $30 \%$ in scenario B. This transfer values applies to the vehicles with an occupancy between 90 and $100 \%$ of its load capacity and despise the transfer of goods from the vehicles with lower occupations.

They have also established a percentage of use of HGV of 42 tons GVM and HGV of 44 tons GVM. This is given that not all HGV of 40 tons GVM will go directly to a full load to exhaust the capacity of the vehicle, but there will be a progressive implementation to HGV of 42 tons GVM and HGV of 44 tons GVM.

Thus, in scenario A, vehicles captured from vehicles traveling with an occupancy between 90 and $100 \%$ account for $33 \%$ of HGV with 42 tons GVM and $67 \%$ of HGV with 44 tons GVM. Also in scenario A, the vehicles captured from vehicles traveling with an 
occupancy rate of $100 \%$ load capacity account for $25 \%$ of HGV with 42 tons GVM and $75 \%$ of $\mathrm{HGV}$ with 44 tons GVM.

For scenario B the values are similar, considering also that vehicles captured from vehicles traveling with an occupancy between 90 and 100\% account for 33\% of HGV with 42 tons GVM and $67 \%$ of HGV with 44 tons GVM. Similarly, in stage B, vehicles captured from vehicles traveling with an occupancy rate of $100 \%$ load capacity account for $30 \%$ of $\mathrm{HGV}$ with 42 tons GVM and $70 \%$ of $\mathrm{HGV}$ with 44 tons GVM.

These scenarios presented here apply to data from the Permanent Survey on Transport of Goods by Road (EPTMC) referred to the year 2011, which will be the baseline for all calculations.

\subsection{Increased productivity of vehicles}

One of the elements that must be taken into account when assessing change scenarios proposed in this study is the increased productivity associated with the use of vehicles with greater capacity. This increase in capacity implies a higher profit margin for the transport companies and a reduction of vehicles travelling on the Spanish road network.

Productivity gains in each vehicle trip substituting HGV of 40 tons GVM by one HGV of 42 tons GVM or an HGV of 44 tons GVM (both fully load) can be estimated at $8.2 \%$ and $16.3 \%$ respectively. Similarly, the decrease in the number of vehicles associated with the replacement of HGV of 40 tons GVM by one HGV of 42 tons GVM or an HGV of 44 tons GVM represents a $7.5 \%$ or $14 \%$.

\subsection{Environmental impact. Reducing greenhouse gases}

HGV of 44 tons GVM are very similar to that of 40 tons GVM in their physical configuration, but due to the increase in total vehicle weight we will have lower engine performance, expressed in increased fuel consumption per kilometer.

Because of this increase in consumption we will also have an increase in pollutant emissions (GHG) associated with these vehicles, which otherwise will be offset by the decline in vehicle kilometers associated with the use of this type of vehicle.

Applying the values of these emissions by type of vehicle and velocity (obtained from the "Guia pràctica per al càlcul d'emissions de gasos amb efecte d'hivernacle") to the different scenarios proposed we can obtain the environmental balance between the use of HGV of 40 tons GVM or the combined use of HGV with 42 tons GVM and HGV with 44 tons GVM.

In the calculations we have used the emissions values corresponding to the average speed of vehicles. They have been applied values of diesel articulated vehicles 34-40 tons GVM for $\mathrm{HGV}$ of 40 tons GVM, and values of diesel articulated vehicle 40-50 tons GVM for HGV of 42 and 44 tons GVM.

The results show that the use of HGV with 44 tons GVM representing a decrease of pollutant emissions associated with them, which can be estimated at 105,249 tons of CO2 annually in scenario A and 129,340 tons of CO2 per year in Scenario B. These emission reductions correspond to a decrease of $5.01 \%$ for stage A and $4.62 \%$ in scenario B compared to the use of $\mathrm{HGV}$ with 40 tons GVM. 


\subsection{Increase in variable operating costs of vehicles}

As mentioned earlier, HGV of 44 tons GVM are very similar to that of 40 tons GVM physical configuration, but due to the increase in total vehicle weight, we will have a lower yield in the operating parameters of the vehicle. This results in increased fuel consumption kilometer, increased tire wear, increased frequency of repairs and an increase in the cost of vehicle maintenance.

The basic values for comparison of the use of the two types of vehicles are obtained from the software ACOTRAM, which gives us the values of the operating costs of HGV (based on the "Observatorio de costes de transporte de mercancías por carretera"). The values used correspond to an articulated vehicle of general cargo with 40 tons GVM, and the prices referred to January 31, 2011 (all prices considered VAT).

For comparison we need the same values for an articulated vehicle general cargo of 44 tons GVM. We used here the values of variation of costs set out in the report "Rapport sur les économiques you conséquences d'un passage éventuel 44 tonnes" from the French Comité National Routier.

With these increment values can be set values of operation costs for an articulated vehicle general cargo 44 tons GVM, with prices referred to January 31, 2011 (all prices considered VAT).

Thus is obtained that the use of articulated vehicles general cargo 44 tons GVM results in an increase of operating costs variables of $6.2 \%$ regarding the use of articulated vehicles general cargo 40 tons GVM, with prices referred to January 31, 2011.

Considering only this variation of the variable operating costs of vehicles we can establish that the total cost of vehicle operating freight would increase from a value of $1,046 € / \mathrm{km}$ with $\mathrm{HGV}$ of 40 tons GVM to $1.076 € / \mathrm{km}$ route with $\mathrm{HGV}$ of 44 tons GVM, representing an increase of costs of $2.86 \%$ per veh-km (which includes the total kilometers traveled by vehicles, either with or without load).

In the same way, we can also calculate what will be the variation in costs per ton transported and kilometer. The values obtained are (by applying a load capacity of 24.5 tons for an $\mathrm{HGV}$ with 40 tons GVM, and 28.5 tons for an $\mathrm{HGV}$ with 44 tons GVM) a value of $0.043 € / \mathrm{t}-\mathrm{km}$ with $\mathrm{HGV}$ with 40 tons $\mathrm{GVM}$ and a value of $0.038 € / \mathrm{t}-\mathrm{km}$ with HGV with 44 tons GVM, representing a decrease of $11.63 \%$ costs per $\mathrm{t}-\mathrm{km}$.

Applying these values of variables operating costs to the different scenarios presented in this study the balance between the use of HGV with 44 tons GVM and HGV with 40 tons GVM is obtained.

Thus, the use of HGV with 44 tons GVM represents a decrease of variable operating costs, which can be estimated at $128 \mathrm{M} €$ a year on scenario $\mathrm{A}$ and $163 \mathrm{M} €$ a year on scenario $\mathrm{B}$. These values correspond to a decrease in variable costs operation of $8.81 \%$ for scenario A and $8.44 \%$ in scenario B compared to the use of HGV with 40 tons GVM.

We can calculate the variation of total costs considering that only vary operating costs. If we do that, we find that the use of HGV with 44 tons GVM represents a decrease of total costs associated with them, which can be estimated at $278 \mathrm{M} €$ a year on scenario A and 
$358 \mathrm{M} €$ a year on scenario $\mathrm{B}$. These values correspond to a decrease in variable costs operation of $10.8 \%$ for scenario A and $10.4 \%$ in scenario B compared to the use of HGV with 40 tons GVM.

\section{CONCLUSIONS}

As you can see by the results of the calculations for the different scenarios proposed, the use of HGV with 40 tons GVM results in an improvement in virtually all operational aspects regarding current vehicles, so it seems appropriate to recommend immediate implementation in the road transport market in Spain.

\section{REFERENCES}

- Comité National Routier. Rapport sur les conséquences économiques d'un éventuel passage a 44 tonnes, 2004.

- Ministerio de Fomento. ACOTRAM 2.4.0.

- Ministerio de Fomento. Encuesta Permanente de Transportes de Mercancías por Carretera (EPTMC), 2011.

- Ministerio de Fomento. Observatorio de costes de transporte de mercancías por carretera, 2011.

- Oficina Catalana del Canvi Climàtic. Guia pràctica per al càlcul d'emissions de gasos amb efecte d'hivernacle (GEH), 2013. 